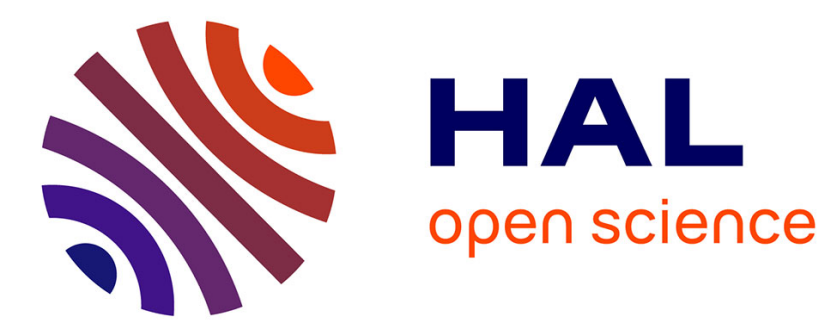

\title{
Does hemithyroidectomy still provide any benefit?
}

Marine Sarfati-Lebreton, Laurence Toqué, Jean-Baptiste Philippe, Jean-Baptiste Finel, Antoine Hamy, Stéphanie Mucci

\section{To cite this version:}

Marine Sarfati-Lebreton, Laurence Toqué, Jean-Baptiste Philippe, Jean-Baptiste Finel, Antoine Hamy, et al.. Does hemithyroidectomy still provide any benefit?. Annales d'Endocrinologie, 2019, 80, pp.101 - 109. 10.1016/j.ando.2018.09.006 . hal-03486666

\section{HAL Id: hal-03486666 https://hal.science/hal-03486666}

Submitted on 20 Dec 2021

HAL is a multi-disciplinary open access archive for the deposit and dissemination of scientific research documents, whether they are published or not. The documents may come from teaching and research institutions in France or abroad, or from public or private research centers.
L'archive ouverte pluridisciplinaire HAL, est destinée au dépôt et à la diffusion de documents scientifiques de niveau recherche, publiés ou non, émanant des établissements d'enseignement et de recherche français ou étrangers, des laboratoires publics ou privés.

\section{다)(1) $(5$}

Distributed under a Creative Commons Attribution - NonCommerciall 4.0 International 


\section{Does hemithyroidectomy still provide any benefit?}

\section{L'isthmolobectomie apporte-t-elle encore des bénéfices ?}

Marine Sarfati-Lebreton, Laurence Toqué, Jean-Baptiste Philippe, Jean-Baptiste Finel, Antoine Hamy, Stéphanie Mucci

CHU d'Angers, Service de Chirurgie Viscérale et Endocrinienne, 4 rue Larrey, 49100, Angers, France

Tel : 0241353618 ; Fax : 0241354742

Corresponding autor : marine.lebreton49@gmail.com

Travail présenté en communication affichée lors du $15^{\text {ème }}$ congrès de l'Association Francophone de Chirurgie Endocrinienne du 15 au 17 juin 2017 à Nantes, France 


\begin{abstract}
Objectives: Multinodular goiter is a common disorder, found in $5 \%$ of the general population. If only one thyroid lobe is affected, hemithyroidectomy may be preferred to total thyroidectomy, to limit the risk of complications and avoid hormone replacement therapy, but incurs a risk of subsequent completion thyroidectomy. The aim of the present study was to determine whether the arguments in favor of hemithyroidectomy are justified and whether it still provides real benefit.

Methods: A retrospective observational study based on prospective data included all patients who underwent surgery for goiter or nodule in our center between September 2010 and September 2014. Rates of hormone replacement 6 months after hemithyroidectomy, postoperative complications and completion thyroidectomy during the postoperative year due to the discovery of carcinoma were analyzed.

Results: 493 patients were studied: 335 total thyroidectomies, 158 hemithyroidectomies. The rate of hormone replacement 6 months after hemithyroidectomy was $84.4 \%$. The rate of definitive hypocalcemia was $6.3 \%$ in total thyroidectomy and zero in hemithyroidectomy $(P<0.05)$. There was no significant difference between groups in terms of recurrent laryngeal nerve palsy $(1.8 \%$ versus $1.9 \% ; \quad P=1)$ or hematoma $(1.2 \%$ versus $3.5 \% ; \quad P=0.15) . \quad 11.3 \%$ of hemithyroidectomies required completion due to discovery of carcinoma (mean interval between surgeries $3.58 \pm 2.5$ months).

Conclusions: This study suggests that hemithyroidectomy does not in fact avoid hormone replacement and places the patient at risk of completion thyroidectomy. However, it avoided a $6 \%$ rate of hypocalcemia. We would recommend hemithyroidectomy only in case of single toxic or euthyroid nodule with healthy contralateral lobe and/or refusal of hormone replacement by the patient.
\end{abstract}

Keywords: hemithyroidectomy; total thyroidectomy; complications; hormone replacement; completion thyroidectomy

\title{
Résumé
}

Objectifs : Le goitre multinodulaire est une pathologie fréquente, de l'ordre de $5 \%$ de la population générale. Si un seul lobe thyroïdien est atteint, l'isthmolobectomie peut être préférée à une thyroïdectomie totale pour diminuer les risques de complications et éviter la supplémentation hormonale, mais expose le patient à un risque de totalisation. Le but de cette étude est de savoir si ces arguments sont justifiés et s'il reste vraiment un intérêt à l'isthmolobectomie.

Méthodes : Nous avons réalisé une étude observationnelle rétrospective basée sur des données recueillies de façon prospective. Nous avons étudié tous les patients opérés d'un goitre ou nodule thyroïdien dans notre centre entre septembre 2010 et septembre 2014. Nous avons analysé le taux de supplémentation hormonale à 6 mois après isthmolobectomie, les complications postopératoires et le taux de totalisation dans l'année dû à la découverte d'un carcinome.

Résultats: Nous avons étudié 493 patients (335 thyroïdectomies totales et 158 isthmolobectomies). Le taux de supplémentation hormonale était de $84,4 \%$ à 6 mois de l'isthmolobectomie. Nous avons trouvé un taux d'hypocalcémie définitive de $6,3 \%$ parmi les cas de thyroïdectomies totales et aucun parmi les isthmolobectomies $(p<0,05)$. II n'y avait pas de différence significative en terme de paralysie récurrentielle $(1,8 \%$ versus $1,9 \% ; p=1)$ ou d'hématome $(1,2 \%$ contre $3,5 \% ; p=0,15)$. Au total, $11,3 \%$ des isthmolobectomies ont été totalisées en raison de la découverte d'un carcinome, à $3.58 \pm 2.5$ mois en moyenne après la première opération. 
Conclusions : Cette étude suggère que l'isthmolobectomie n'empêche en fait pas la supplémentation hormonale et expose le patient au risque d'une totalisation secondaire. Néanmoins, elle prévient $6 \%$ d'hypocalcémies. Nous recommanderions une isthmolobectomie devant un nodule unique (toxique ou euthyroïdien) avec un lobe controlatéral sain et/ou un refus de supplémentation hormonale du patient.

Mots clés : Isthmolobectomie ; thyroïdectomie totale ; complications ; supplémentation hormonale ; totalisation

\section{Manuscript:}

\section{Introduction:}

Multinodular goitre is a common disorder: it occurs in 5\% of the general population, and up to $15 \%$ in endemic areas defined as areas with an iodine deficiency (1). The incidence of chance discovery of carcinoma ranges from 3 to $16 \%$ according to studies (2), regardless of whether there is one nodule or several. As it grows, the goitre can cause symptoms as well as aesthetic discomfort (3). The challenge with assessing goitre or a single nodule is not to dismiss a possible cancer. If only one side is affected, physicians can consider performing only a hemithyroidectomy (HT).

The benefit of a HT would be to avoid serious complications such as definitive hypoparathyroidism or a bilateral recurrent nerve lesion. In literature, the risk of a unilateral nerve lesion is less than $2 \%$ for total thyroidectomy (TT) and HT (1). The risk of definitive hypoparathyroidism (hormone supplementation for more than 6 months) is around 3\% for TT and $0 \%$ for $\mathrm{HT}$ (4). Another benefit of $\mathrm{HT}$ is to protect the patient from definitive hypothyroidism (25\% in literature (5)) and prevent the patient from the necessity of a lifelong levothyroxine. However, in the case of a unilateral multinodular goitre or with only contralateral micronodules, the benefit of a HT is still uncertain, assuming that goitre is a disorder that affects the "thyroid" organ, we may fear a recurrence of contralateral nodules upon surgery. In carrying out this study, we wanted to compare TT and HT in terms of 
benefits for the patient within the framework of a benign disorder such as a multinodular goitre or a single nodule.

The main goal of this study was to analyse the rate of patients with hormone supplementation at 6 months following a HT. The secondary goals are the analysis of surgical complications in the case of a HT and a TT and the study of the rate of carcinomas discovered on the definitive anatomical pathology and the comparison between the two surgeries as well as the rate of patients requiring secondary surgery for completion thyroidectomy with or without lymph node dissection.

\section{Materials and methods:}

We carried out an observational study based on prospective data. We analysed all the cervicotomies performed in the Digestive and Endocrine Surgery Department of a single centre between September 2010 and September 2014. Preoperative, perioperative and postoperative data during hospitalisation were collected prospectively. Long-term data relating to the follow-up of complications and hormone supplementation were collected retrospectively. We included patients with a multinodular goitre or a single nodule. We excluded patients with cancers that were discovered upon fine-needle aspiration biopsy (FNA) (that required immediate total thyroidectomy with lymph node dissection), Grave's disease, parathyroidectomy associated and patients with a history of partial thyroidectomy. Preoperative data (such as age, gender, surgical indications, the number of patients who had undergone FNA as well as the results and thyroid function) were collected. Postoperative complications as well as definitive anatomopathological results were analysed.

As concerns hypocalcaemia, we analysed patients with a calcium phosphate supplementation due to hypocalcaemia (defined by a rate of corrected calcium below $2 \mathrm{mmol} / \mathrm{L}$ ) and/or symptomatic hypocalcaemia (tingling in fingers or lips or even tetany). We analysed the 
presence of a supplementation at 1 and 6 months, defining a definitive hypoparathyroidism for the latter. As concerns laryngeal complications, we analysed the rate of patients with a modified voice following surgery. These patients underwent an examination with video endoscopy in order to analyse the mobility of the vocal cords. Definitive recurrent laryngeal nerve palsy was defined as a palsy of the vocal cords at 6 months following surgery. We also studied the presence of a postoperative haematoma.

As concerns hormone replacement therapy, we routinely gave a supplement of 50 micrograms of L-thyroxine for patients having undergone a HT and 100 micrograms for patients having undergone TT. The patient then consulted their endocrinologist a month after surgery. The decision on whether further treatment was necessary was left to the endocrinologist's discretion. We studied the number of patients with hormone supplementation at 6 months.

The definitive anatomopathological results relating to the thyroidectomy specimens were analysed. The files of patients who presented a malignant illness were presented at multidisciplinary consultation meetings and treatment was adapted accordingly case by case. According to the french guidelines (6), a completion thyroidectomy was recommended for all cancer greater than $1 \mathrm{~cm}$ and multifocal papillary thyroid microcarcinoma (PTMC) if their sum diameter was greater than $1 \mathrm{~cm}$ especially for radioactive iodine (RAI) therapy for differentiated thyroid carcinoma.

Statistical analysis was performed using SPSS software by the $\chi^{2}$-test, Fisher-test or by Student's $t$-test and the alpha risk defined by $\mathrm{p}<0.05$.

\section{Results:}


Between September 2010 and September 2014, 737 thyroid procedures were performed in the centre. We excluded 244 patients from the analysis for the reasons mentioned (Figure 1). We therefore analysed 493 patients, including 335 TT and 158 HT (91 rights and 66 left).

Preoperatory data are given in Table 1 . Most patients were euthyroid and had not undergone any treatment before the surgery. The main indications were a single nodule in the case of HT $(91.1 \% ; 144 / 158)$ and a multinodular goitre in the case of TT $(77.3 \% ; 259 / 335)$. A total of $20.9 \%$ (33/158) of patients with HT did not have a perfectly healthy contralateral lobe on the neck ultrasonography. FNA was not performed before surgery in 38.5\% (129/335) of patients in the case of TT and in $15.8 \%(25 / 158)$ of patients in the case of HT $(\mathrm{p}<0.05)$.

\section{Hormone supplementation:}

As concerns the primary endpoint, we found the proportion of patients who underwent hormone supplementation to be $84.8 \%$ in the HT group (134/158) at 6 months. After excluding 18 patients who underwent completion thyroidectomy in the years following a discovery of cancer, the proportion of remaining patients with L-thyroxine was $82.3 \%$ in HT population (116/140) (Table 2).

\section{Histology:}

Definitive diagnoses were essentially benign, mainly of goitres in the case of TT $(67.5 \%$; $226 / 335)$ and of adenomas in the case of HT (64.6\%; 102/158), which is consistent with surgical indications. However, cancers were found, mainly papillary (PTC) $(21.8 \%$ in the case of TT $(73 / 335)$ and $9.5 \%$ in the case of HT $(15 / 158) ;(\mathrm{p}<0.05))$. Most of which were micropapillary (PTMC) (carcinomas smaller than $1 \mathrm{~cm}$ or the sum of which is smaller than $1 \mathrm{~cm})$. Out of all the FNA performed, only $29.1 \%$ resulted in discovering a cancer in the punctured lobe (16/55). An frozen section was performed mainly in the case of HT $(29.7 \%$ (47/158) versus $7.8 \%$ for TT $(26 / 335) ; \mathrm{p}<0.05)$, however a conclusion which could change 
the operative gesture was only reached in $50 \%$ of cases of TT and $53.2 \%$ of cases of HT (13/26 and 25/47, respectively). This difference was not significant $(\mathrm{p}=0.95)$.

\section{Completion thyroidectomy:}

Among the patients who underwent a HT, 11.4\% (18/158) had completion thyroidectomy due to the discovery of a carcinoma upon definitive histological analysis. Their histological analysis is summarised in Table 3. Most of these patients underwent FNA, the results of which were "suspicious for malignancy" (Bethesda IV) in only half of the cases. Frozen section procedure was non-contributory for all patients who were subject to it. The average time to completion thyroidectomy was $3.58+/-2.5$ months (minimum 1 month and maximum 11 months because the patient did not initially want further surgery).

\section{Complications:}

Postoperative complications are given in Table 4. As concerns hypocalcaemias, we found $6.3 \%(21 / 335)$ at 6 months out of the TT and there were no cases of hypocalcaemia among patients who underwent a HT $(\mathrm{p}<0.05)$.

As concerns recurrent laryngeal nerve palsies, the difference was not significant between cases of TT and cases of HT, whether in terms of modified voice, palsy confirmed with video endoscopy or definitive palsy $(1.8 \%(6 / 335)$ for TT versus $1,9 \%(3 / 158)$ for HT ; $p=1)$. The difference between the rates of haematomas was not significant $(1.2 \%(4 / 335)$ versus $3.2 \%$ $(5 / 158) ; \mathrm{p}=0.15)$. We found $5.6 \%$ of hypocalcaemia after completion thyroidectomy $(1 / 18)$ and no recurrent laryngeal nerve palsy or haematomas.

\section{Discussion:}


The 2015 American Thyroid Association Management Guidelines leave some freedom to the surgeon to choose between TT and HT for nodule management. According to these recommendations, HT is the recommended initial surgical approach for a solitary, cytologically indeterminate nodule. They also note, however, that TT may be preferred in patients with indeterminate nodules who have bilateral nodular disease or those who prefer to undergo bilateral thyroidectomy to avoid the possibility of requiring future surgery on the contralateral lobe. (recommendations 19 and 20) (7). We understand that the choice between HT and TT is more or less left to the discretion of the physician and patient. Especially given that the latest French guidelines from 2011 say that: "Lobectomy is not adapted to the treatment of cancers and to the prevention of relapses in the event of a benign nodule" (8). In order to answer the question relating to the benefits of HT, we therefore sought to answer several other questions:

\section{Hormone supplementation after hemithyroidectomy:}

As far as the rate of L-thyroxine supplementation after surgery is concerned, we found our rate to be very high at over $80 \%$. A 2012 meta-analysis which included 30 studies (i.e. 4900 patients), found a $22 \%$ incidence of postoperative hypothyroidism in HT population (CI95\% : 19-27\%), with euthyroid patients before surgery (9). However, there are discrepancies in literature with regard to the definition of hypothyroidism: it can be clinical (high TSH with low free T3 or T4) or subclinical (high TSH and free T3 or T4 in the lower norm), as well as with regard to the time to the TSH assay (1 to 3 months after surgery). However, we can reasonably assume that all our patients subject to hormone supplementation did not suffer from hypothyroidism. The explanation lies in the fact that hormonal supplementation prevents hypertrophy of the remaining lobe through feed-back and therefore reduces the risk of the nodules relapsing. This hormonal effect is debated in literature. In 2010, a prospective study found $1.4 \%$ recurrence versus $16.7 \%(\mathrm{p}<0.05)$ in 75 randomised patients with postoperative 
supplementation versus 75 without hormone therapy, over a 5-year follow-up (10). Several studies took this approach, showing a decrease in the risk of recurrence. However, it has long been known that a low rate of TSH and therefore artificial subclinical hypothyroidism can have negative effects, particularly in terms of cardiac function and bone density $(11,12)$. Moreover, there is a lack of agreement concerning this effect of hormone supplementation. In 2008, a literature review from 1987 to 2007 on this subject cannot conclude (13). In this review, a prospective, randomised study of 202 patients with hormone supplementation versus lack of supplementation, with an average follow-up of 10 years, does not find a significant difference in terms of recurrence (19\% versus $26.5 \%$ ) (14). In contrast, a retrospective study of 632 patients with a history of radiation exposure found $14 \%$ of recurrence in the group with suppressive doses of $\mathrm{T} 4$ and $34.2 \%$ in the group without hormone therapy $(\mathrm{p}<0.05)$ for an average follow-up of 17 years (15). There is a large discrepancy between studies in terms of cohort, follow-up and the definition of recurrence. Moreover, the follow-up is often short, between 1 and 10 years in most cases. We know, however, that suffering from a bilateral thyroid "disease" increases the risk of recurrence. In our study, $20.9 \%$ of patients who underwent HT did not have a healthy contralateral lobe (micronodules, heterogeneity on ultrasonography). Moreover, there is some disparity among cohorts in literature, as well as disparity among countries in which these studies were carried out. Indeed, a factor that is found to be a recurrence risk factor is iodine deficiency (10). Yet France is a country that is considered to be deficient in iodine by the WHO (16), while the United States, for example, is not, which means that we could not compare these two cohorts.

Without consensus in literature or in available guidelines, in our region, there are disparities depending on the endocrinologists who treat patients. Anyway, due to the choice of the endocrinologists $80 \%$ of the patients, who underwent of a HT, will have a hormone supplementation. HT presents benefits for patients who do not want supplementation or those who cannot have it (in countries where supplementation is not refunded or difficult to obtain). 
We can therefore answer that, in France and more particularly in our region, HT does not prevent hormone supplementation, which is often for life, with a risk of recurrence found in literature between 15 and $30 \%$ (13).

\section{Complications after surgery:}

Concerning postoperative complications, our results were variable compared to literature. With regard to hypocalcaemias, the rate of definitive hypoparathyroidism found at 6 months was $6.27 \%$ in our series, for patients with a TT as against $0 \%$ for patients with HT $(\mathrm{p}<0.05)$. These numbers are relatively high compared to literature. Thomusch and al. in 2000 (17) and Duclos and al. in 2012 (4), who present the largest series in literature (7266 and 3574 patients, respectively), found definitive hypocalcaemia rates (with a calcium level lower than 2 $\mathrm{mmol} / \mathrm{L}$ ) of $1.5 \%$ and $2.69 \%$, respectively. They did not find hypocalcaemia following HT. A 2008 literature review that included only benign multinodular goitres, found rates of permanent hypocalcaemia following total thyroidectomy of between $0.2 \%$ and $10.5 \%$, but most often closer to $3 \%$ (2). Unfortunately, we could only analyse the rate of patients with a calcium or vitamin D supplementation, which implies hypocalcaemia, and not directly the rate of calcium or PTH at 6 month, which can overestimate the rate. There was no significant difference between TT and completion thyroidectomy $(6.27 \%$ versus $5.6 \%$ respectively; $\mathrm{p}=0.15)$

As concerns laryngeal lesions, the rate of patients with a persisting palsy is $1.8 \%$ ( 6 patients) in the TT group and $1.9 \%$ (3 patients) in HT group $(\mathrm{p}=1)$. We can conclude that there is no difference with regard to recurrent laryngeal nerve palsy. The risk of recurrent lesions is not twice as high in TT group because in $64 \%$ of cases, the recurrent nerve lesion could be found on the most affected side or the one on which the surgery started. There was no bilateral recurrent palsy in our cohort. These rates are comparable to literature. Thomusch and al. and Duclos and al. found $1.1 \%$ et $2.08 \%$ respectively $(17,4)$. We can therefore consider that it is 
the level of difficulty of the surgery, based on the shape and size of the goitre, which is a risk factor for recurrent nerve lesions and not the thyroidectomy in itself. We believe that performing a thyroidectomy in a patient with a solitary nodule or a unilateral goitre does not place the patient at an excessively high risk of recurrent laryngeal nerve palsy.

However, our rate of laryngeal complication is probably underestimated due to a number of limitations. Indeed, the first limitation is that we did not carry out systematic monitoring through video endoscopy for all patients (18). Recurrent laryngeal nerve palsy can be completely asymptomatic, which is why in the event of further surgery all patients must undergo a preoperative examination. In addition, our study differs from others found in literature in that we did not use recurrent nerve monitoring (NIM) because we do not have access to this technology. Results found in literature are contradictory, several studies, including two meta-analyses, do not demonstrate any advantages of monitoring in terms of reducing permanent recurrent complications compared to visualising the nerve (19-21).

As concerns haematomas, there is no significant difference between our two groups and this rate is comparable to literature (17).

We can therefore answer that total thyroidectomy exposes the patient to a risk of definitive hypocalcaemia with a rate of $6 \%$ in our study, which is not the case with hemithyroidectomy. As concerns recurrent nerve lesions, we believe that it is more the goitre and the difficult nature of the surgery as opposed to the total thyroidectomy that exposes the patient to the risk of palsy. We did not find any cases of bilateral palsy. Similarly, total thyroidectomy does not expose patients to an excessive risk of haematoma.

\section{Completion thyroidectomy:}

One of the indications of thyroid surgery due to goitres or solitary nodules is a histological examination of a suspicious nodule. For the last thirty years, the incidence of thyroid carcinoma has been rising in the world, particularly thanks to improvements in diagnostic 
methods (22). The incidence of carcinomas has also been rising, particularly microcarcinomas (PTMC)(smaller than $1 \mathrm{~cm}$ ) discovered on excised specimens of thyroid tissue (22). A FNA value is recommended in France for all nodules above a TI-RADS score of 3 on neck ultrasonography to classify the nodules according to the Bethesda classification (3). The average sensitivity and specificity of FNA are $83 \%$ and $92 \%$ respectively, and the predictive positive value to differentiate between a malignant and benign nodule is $75 \%$ (23). Bethesda grades V and VI have a malignancy risk of 75 and $100 \%$ respectively; they warrant surgical treatment through TT. The problem remains with grades III and IV as their nature is uncertain, with a risk of malignancy of 5 to $15 \%$ and 15 to $30 \%$ respectively. Surgical treatment for the purpose of histological analysis may be suggested, either HT or a TT. The problem is not to perform surgery on too many patients who actually only have benign lesions. Indeed, thyroid cancer is rare and makes up $1 \%$ of all malignant tumours in France (24). In our cohort, 79 patients $(23.6 \%)$ had unknown cancerous lesions in the TT group and 27 patients $(17.1 \%)$ in HT group especially PTMC (14.9\% of TT versus 5.7\% of HT in our study). These PTMC do not usually bring about a change in treatment. However if the sum of diameter was greater than $1 \mathrm{~cm}$, a completion thyroidectomy was recommended in view of the risk of recurrence (25). Moreover, in our study, in 30\% of cases of cancer in the TT group with FNA, the cancerous side was not the suspicious side which led to the FNA. Finally, 18 patients $(11.4 \%)$ of patients who underwent HT also underwent completion thyroidectomy in the following weeks, after the multidisciplinary consultation meeting, in order to perform RAI. This rate is not negligible and corresponds to $70 \%$ of cancers discovered in dissected tissue in our cohort. The goal of RAI is the ablation of small volumes of tissue to facilitate monitoring of serum thyroglobulin level and the use of diagnostic whole body iodine scans to identify metastasis or in adjuvant therapy to ablate microscopic thyroid cancer tissue to decrease recurrence (26). However, the dosage and the indication of RAI decreases in guidelines especially for patient with low-risk of disease recurrence or persistence (patients 
with intrathyroidal differented thyroid cancer with no extrathyroidal extension, vascular invasion, or metastases and clinical $\mathrm{N} 0$ or $<5$ pathologic $\mathrm{N} 1$ micrometastases $<0.2 \mathrm{~cm}$ in largest dimension) because the benefit-risk balance is not favorable in terms of survival and disease-free survival (2015 ATA guideline recommendation 35 (7)). It decrease the indications of completion thyroidectomies $(7,26)$. With these guidelines, only 5 of 18 patients in our cohort would have been reoperated corresponding of $3.2 \%$ of HT (Table 3). Furthermore, after reviewing the anatomopathology records, 3 cancers discovered after TT and 1 after HT could be considered as "Noninvasive follicular thyroid neoplasm with papillary-like nuclear features" (NIFTP) and not like a cancer.

To decrease this rate of completion thyroidectomy, we need to be able to increase the rate of suspicious cancers before surgery so that the surgery can be adapted. In particular, we need to decrease the rate of patients undergoing surgery due to a nodule showing atypias (Bethesda III and IV). This rate is $20.3 \%$ in the TT group and $24.7 \%$ in HT group in our study. An appealing solution seems to be the performance of a HT combined with frozen section analysis and completion thyroidectomy in the event of cancer. In reality, we think this option is not a solution. In our study, a frozen section analysis was carried out in $7.8 \%$ of cases of TT and $29.7 \%$ of cases of HT that resulted in a useful conclusion in only $50 \%$ of cases. This is naturally attributable to the histology of thyroid cancers. Papillary cancers are defined by cellular atypias which can most often be seen in FNA with a positive predictive value between 75 and $98.6 \%$ (27). Vesicular cancers do not have nuclear atypias but they have the features of carcinoma, particularly capsular effractions and vascular invasions. Cytological diagnosis is almost impossible, with a positive predictive value of $26.1 \%$ (27). In literature, the sensitivity of frozen section analysis of follicular lesions is low, around 17\% (28).

It would therefore be beneficial to more effectively predict cancerous lesions before surgery, seeing as $76.4 \%$ of patients in the TT group and $82.3 \%$ of patients in the HT group undergo surgery for benign lesions. Preoperative FNA should always be performed, even in the event 
of a multinodular goitre, because this helps determine the correct type of surgery (total thyroidectomy, lymph node dissection, etc.).

Indeed, completion thyroidectomy for cancer or nodules recurrence creates a cost for society, which is not counterbalanced by the lack of hormonal supplementation. In 2014, a study of direct costs generated over 5 years, taking into account the risks of complications found in the literature, as well as the risks of recurrence and reoperation. This study is clearly in favor of TT (29). Similarly, another study in 2007 found a clear financial advantage in favor of TT in papillary thyroid cancer with a low risk of recurrence over 20 years of follow-up (30). In addition, for these two studies there is no supplementation in thyroid hormones after HT. This, with the rate of $80 \%$ supplementation in this case in our cohort, further reduces the financial interest of HT.

\section{Conclusion}

We can conclude that in our study, hemithyroidectomy results in $80 \%$ of the hormonal supplementation for life with L-thyroxine due to the choice of endocrinologists, a risk of recurrence and a new surgery, without avoiding lesions recurrent nerve. It avoids, however, $6 \%$ of definitive hypocalcemia. In addition, the risk of completion thyroidectomy is $11 \%$ following the discovery of a cancer even if this rate decreases with the 2015 ATA guidelines. We think that hemithyroidectomy have still any benefits but limited. Among the indications we retain patients who have a solitary nodule with a healthy contralateral lobe and who do not wish to have hormone supplementation for life, as well as patients who do not have the possibility of receiving this supplementation. There is another indication: the suspicion of recurrent lesions, which would require hemithyroidectomy in order to prevent bilateral palsy. For all other indications, we believe that a complete preoperative examination must be carried 
out and that fewer patients should undergo surgery, but that the surgery should often be a total thyroidectomy.

The authors declare that they have no competing interest. 


\section{References}

1. Lang BH-H, Lo C-Y. Total thyroidectomy for multinodular goiter in the elderly. Am J Surg. 2005 Sep;190(3):418-23.

2. Agarwal G, Aggarwal V. Is Total Thyroidectomy the Surgical Procedure of Choice for Benign Multinodular Goiter? An Evidence-Based Review. World J Surg. 2008 Jul;32(7):1313-24.

3. Daumerie C, Coche E, Galant C, Wallon J. Consensus 'revisité' dans l'approche du nodule thyroïdien. Mises Au Point Clin Endocrinol. 2011 Nov;

4. Duclos A, Peix J-L, Colin C, Kraimps J-L, Menegaux F, Pattou F, et al. Influence of experience on performance of individual surgeons in thyroid surgery: prospective cross sectional multicentre study. BMJ. 2012;344.

5. Stoll SJ, Pitt SC, Liu J, Schaefer S, Sippel RS, Chen H. Thyroid hormone replacement after thyroid lobectomy. Surgery. 2009 Oct;146(4):554-60.

6. Borson-Chazot F, Bardet S, Bournaud C, Conte-Devolx B, Corone C, D'Herbomez M, et al. Guidelines for the management of differentiated thyroid carcinomas of vesicular origin. Ann Endocrinol. 2008 Dec;69(6):472-86.

7. Haugen BR, Alexander EK, Bible KC, Doherty GM, Mandel SJ, Nikiforov YE, et al. 2015 American Thyroid Association Management Guidelines for Adult Patients with Thyroid Nodules and Differentiated Thyroid Cancer: The American Thyroid Association Guidelines Task Force on Thyroid Nodules and Differentiated Thyroid Cancer. Thyroid. 2015 Oct 14;26(1):1-133.

8. Wémeau, Sadoul, d'Herbomez, Monpeyssen, Tramalloni. Recommandations de la Société française d'endocrinologie pour la prise en charge des nodules thyroïdiens. Presse Médicale. 2011 Sep;40(9):793-826.

9. Verloop H, Louwerens M, Schoones JW, Kievit J, Smit JWA, Dekkers OM. Risk of Hypothyroidism following Hemithyroidectomy: Systematic Review and Meta-Analysis of Prognostic Studies. J Clin Endocrinol Metab. 2012 Apr 17;97(7):2243-55.

10. Barczyński M, Konturek A, Gołkowski F, Hubalewska-Dydejczyk A, Cichoń S, Nowak W. Five-year follow-up of a randomized clinical trial of unilateral thyroid lobectomy with or without postoperative levothyroxine treatment. World J Surg. 2010 Jun;34(6):1232-8.

11. Biondi $B$, Fazio $S$, Palmieri EA, Tremalaterra R, Angellotti $G$, Bonè $F$, et al. Effects of chronic subclinical hyperthyroidism from levothyroxine on cardiac morphology and function. Cardiol Rome Italy. 1999 May;44(5):443-9.

12. Bauer DC, Ettinger B, Nevitt MC, Stone KL, Study of Osteoporotic Fractures Research Group. Risk for fracture in women with low serum levels of thyroid-stimulating hormone. Ann Intern Med. 2001 Apr 3;134(7):561-8. 
13. Moalem J, Suh I, Duh Q-Y. Treatment and Prevention of Recurrence of Multinodular Goiter: An Evidence-based Review of the Literature. World J Surg. 2008 Jul;32(7):130112.

14. Hegedüs L, Nygaard B, Hansen JM. Is routine thyroxine treatment to hinder postoperative recurrence of nontoxic goiter justified? J Clin Endocrinol Metab. 1999 Feb;84(2):756-60.

15. Subbiah S, Collins BJ, Schneider AB. Factors related to the recurrence of thyroid nodules after surgery for benign radiation-related nodules. Thyroid Off J Am Thyroid Assoc. 2007 Jan;17(1):41-7.

16. Andersson M, Takkouche B, Egli I, Allen HE, de Benoist B. Current global iodine status and progress over the last decade towards the elimination of iodine deficiency. Bull World Health Organ. 2005 Jul;83(7):518-25.

17. Thomusch O, Machens A, Sekulla C, Ukkat J, Lippert H, Gastinger I, et al. Multivariate analysis of risk factors for postoperative complications in benign goiter surgery: prospective multicenter study in Germany. World J Surg. 2000 Nov;24(11):1335-41.

18. Jeannon J-P, Orabi AA, Bruch GA, Abdalsalam HA, Simo R. Diagnosis of recurrent laryngeal nerve palsy after thyroidectomy: a systematic review. Int J Clin Pract. 2009 Apr 1;63(4):624-9.

19. Barczyński M, Konturek A, Cichoń S. Randomized clinical trial of visualization versus neuromonitoring of recurrent laryngeal nerves during thyroidectomy. Br J Surg. 2009 Mar 1;96(3):240-6.

20. Higgins TS, Gupta R, Ketcham AS, Sataloff RT, Wadsworth JT, Sinacori JT. Recurrent laryngeal nerve monitoring versus identification alone on post-thyroidectomy true vocal fold palsy: A meta-analysis. The Laryngoscope. 2011 May 1;121(5):1009-17.

21. Rulli F, Ambrogi V, Dionigi G, Amirhassankhani S, Mineo TC, Ottaviani F, et al. Metaanalysis of recurrent laryngeal nerve injury in thyroid surgery with or without intraoperative nerve monitoring. Acta Otorhinolaryngol Ital. 2014;34(4):223.

22. Leenhardt L, Grosclaude $P$, Chérié-Challine L, Thyroid Cancer Committee. Increased incidence of thyroid carcinoma in france: a true epidemic or thyroid nodule management effects? Report from the French Thyroid Cancer Committee. Thyroid Off J Am Thyroid Assoc. 2004 Dec;14(12):1056-60.

23. Haute Autorité de Santé - 2010 - ALD 30 cancer de la thyroïde.pdf [serial online]. [cited 2016 Aug 18]. Available from: https://www.has-sante.fr/portail/jcms/c_969305/fr/aldn-30-cancer-de-la-thyroide

24. Colonna M, Bossard N, Guizard A-V, Remontet L, Grosclaude P, le réseau FRANCIM. Descriptive epidemiology of thyroid cancer in France: incidence, mortality and survival. Ann Endocrinol. 2010 Mar;71(2):95-101. 
25. Xue S, Wang P, Liu J, Chen G. Total thyroidectomy may be more reasonable as initial surgery in unilateral multifocal papillary thyroid microcarcinoma: a single-center experience. World J Surg Oncol [Internet]. 2017 Mar 16;15. Available from: https://www.ncbi.nlm.nih.gov/pmc/articles/PMC5356282/

26. Marti JL, Morris LGT, Ho AS. Selective use of radioactive iodine (RAI) in thyroid cancer: No longer 'one size fits all'. Eur J Surg Oncol EJSO [Internet]. 2017 May 3; Available from: http://www.sciencedirect.com/science/article/pii/S0748798317304444

27. Bongiovanni M, Spitale A, Faquin WC, Mazzucchelli L, Baloch ZW. The Bethesda System for Reporting Thyroid Cytopathology: A Meta-Analysis. Acta Cytol. 2012;56(4):333-9.

28. Lumachi F, Borsato S, Tregnaghi A, Marino F, Polistina F, Basso SMM, et al. FNA Cytology and Frozen Section Examination in Patients with Follicular Lesions of the Thyroid Gland*. Anticancer Res. 2009 Dec 1;29(12):5255-7.

29. Corso C, Gomez X, Sanabria A, Vega V, Dominguez LC, Osorio C. Total thyroidectomy versus hemithyroidectomy for patients with follicular neoplasm. A cost-utility analysis. Int J Surg. 2014 Aug;12(8):837-42.

30. Shrime MG, Goldstein DP, Seaberg RM, Sawka AM, Rotstein L, Freeman JL, et al. Costeffective management of low-risk papillary thyroid carcinoma. Arch Otolaryngol Head Neck Surg. 2007 Dec;133(12):1245-53. 
Table 1: Preoperative characteristics of patients

\begin{tabular}{|c|c|c|c|}
\hline Parameters & $\begin{array}{c}\text { Total } \\
\text { thyroidectomies } \\
\mathrm{N}(\%) \\
\mathrm{N}=335\end{array}$ & $\begin{array}{l}\text { Hemithyroidectomies } \\
\qquad \begin{array}{c}\mathrm{N}(\%) \\
\mathrm{N}=158\end{array}\end{array}$ & p-values \\
\hline Female gender & $256(76.4)$ & $123(77.8)$ & 0.79 \\
\hline Average age & $52.2( \pm 13.9)$ & $46.5( \pm 14.3)$ & $<0.05$ \\
\hline Medical history & & & \\
\hline Obesity & $103(31.3)$ & $24(15.3)$ & $<0.05$ \\
\hline Cervicotomy (other than thyroid) & $13(3.9)$ & $0(0)$ & - \\
\hline Anticoagulant/antiplatelet agents & $38(11.3)$ & $8(5.1)$ & $<0.05$ \\
\hline Preoperative TSH & & & 0.04 \\
\hline Euthyroid & $234(69.9)$ & $121(76.6)$ & \\
\hline Hypothyroid & $21(6.3)$ & $6(3.8)$ & \\
\hline Hyperthyroid & $38(11.3)$ & $8(5.1)$ & \\
\hline Unknown & $42(12.5)$ & $23(14.6)$ & \\
\hline Surgical indication & & & $<0.05$ \\
\hline Single nodule & $20(6.0)$ & $144(91.1)$ & \\
\hline Euthyroid multinodular goitre & $259(77.3)$ & $12(7.6)$ & \\
\hline Toxic multinodular goitre & $51(15.2)$ & $1(0.63)$ & \\
\hline MEN 2 prophylaxis & $2(0.6)$ & $0(0)$ & \\
\hline Thyroiditis due to Cordarone & $0.6(2)$ & $0(0)$ & \\
\hline $\begin{array}{l}\text { Unhealthy contralateral lobe (heterogeneity, } \\
\text { micronodules, etc.) } \\
\text { Fine-needle aspiration (FNA) }\end{array}$ & $326(97.3)$ & $33(20.9)$ & $<0.05$ \\
\hline Not performed & $129(38.5)$ & $25(15.8)$ & $<0.05$ \\
\hline Results & $206(61.5)$ & $133(84.2)$ & 0.11 \\
\hline Bethesda I (non-contributory) & $35 / 206(17.0)$ & $31 / 133(23.8)$ & \\
\hline Bethesda II (benign) & $91 / 206(44.2)$ & $60 / 133(46.2)$ & \\
\hline Bethesda III-IV (atypias) & $68 / 206(33.0)$ & $39 / 133(30)$ & \\
\hline Bethesda V-VI (suspicious/malignant) & $12 / 206(5.8)$ & $2 / 133(1.5)$ & \\
\hline
\end{tabular}


Table 2: Postoperative data: hormone supplementation and diagnosis

\begin{tabular}{|l|c|c|c|}
\hline \multicolumn{1}{|c|}{ Parameters } & $\begin{array}{c}\text { Total } \\
\text { thyroidectomies } \\
\mathrm{N}(\%)\end{array}$ & $\begin{array}{c}\text { Hemithyroidectomies } \\
\mathrm{N}(\%)\end{array}$ & p-values \\
& $\mathrm{N}=335$ & $\mathrm{~N}=158$ & \\
\hline $\begin{array}{l}\text { Postoperative hormone supplementation at } 6 \\
\text { months }\end{array}$ & $335(100)$ & $134(84.8)$ & $<0.05$ \\
Supplementation for patients who did not & & $116(82.3)$ & $<0.05$ \\
undergo completion thyroidectomy (140) & & & \\
Definitive diagnoses & & & \\
Multinodular goitre & $226(67.5)$ & $28(17.7)$ & $<0.05$ \\
Adenoma & $28(8.4)$ & $102(64.6)$ & $<0.05$ \\
Papillary carcinoma (PTC) & $73(21.8)$ & $15(9.5)$ & $<0.05$ \\
Micropapillary (<1cm) & $50(15.0)$ & $9(5.7)$ & $<0.05$ \\
Papillary > 1cm & $23(6.9)$ & $6(3.8)$ & 0.17 \\
Follicular carcinoma (FTC) & $3(0.9)$ & $11(7.0)$ & $<0.05$ \\
Medullar carcinoma (MTC) & $3(0.9)$ & $1(0.6)$ & 0.54 \\
Metastasis & $0(0)$ & $1(0.6)$ & - \\
Thyroiditis & $2(0.6)$ & $0(0)$ & - \\
Performance of an frozen section analysis & $26(7.8)$ & $47(29.7)$ & $<0.05$ \\
Contributory (malignant/benign) & $13 / 26(50)$ & $25 / 47(53.2)$ & 0.95 \\
Concordance of localisation between cancer & $16 / 55(29.1)$ & - & \\
and FNA (out of 55 patients) & & & \\
\hline
\end{tabular}


Table 3: Histological analysis of 18 hemithyroidectomies with completion thyroidectomie

\begin{tabular}{|c|c|c|c|c|c|c|c|}
\hline Surgical indication & FNA & $\begin{array}{l}\text { Frozen } \\
\text { section } \\
\text { analysis }\end{array}$ & $\begin{array}{l}\text { Cancer } \\
\text { size } \\
(\mathrm{cm})\end{array}$ & $\begin{array}{l}\text { Discovery } \\
\text { mode }\end{array}$ & Histology of cancer & $\begin{array}{c}\text { ATA } 2015 \\
\text { risk }\end{array}$ & $\begin{array}{c}\text { ATA } 2015 \\
\text { completion } \\
\text { thyroidectomy }\end{array}$ \\
\hline Nodule $>3 \mathrm{~cm}$ & no & no contributory & 3,7 & incidentaly & FTC with capsular invasion no vascular invasion pT2 & low & no \\
\hline Nodule $>3,5 \mathrm{~cm}$ & Bethesda II & no & 3,5 & incidentaly & Encapsulated PTC with capsular and vascular invasion pT2 & intermediate & yes \\
\hline Nodule Bethesda IV & Bethesda IV & no contributory & 2 & & Minimally invasive FTC pT1b & low & no \\
\hline Nodule Bethesda IV & Bethesda IV & no & 2 & & FTC with minimal vascular invasion $\mathrm{pT} 1 \mathrm{~b}$ & low & no \\
\hline Nodule $>3 \mathrm{~cm}$ & Bethesda II & no & 2,5 & incidentaly & Minimally invasive FTC pT2 & low & no \\
\hline Several FNA Bethesda I & Bethesda I & no contributory & 0,6 & incidentaly & Medular thyroid cancer $0,6 \mathrm{~cm}$ & - & yes \\
\hline Nodule $>3 \mathrm{~cm}$ & Bethesda II & no & 2,6 & incidentaly & Minimally invasive FTC with minimal vascular invasion pT2 & low & no \\
\hline Multinodular goitre & Bethesda IV & no & $1,8+0,3$ & incidentaly & Intrathyroidal PTC no vascular invasion pT1b + PTMC & low & no \\
\hline Nodule Bethesda IV & Bethesda IV & no contributory & 1,2 & incidentaly & Encapsulated follicular variant of PTC pT1b & low & no \\
\hline Nodule $>3 \mathrm{~cm}$ & Bethesda II & no & 3,6 & incidentaly & Intrathyroidal PTC pT2 with microscopic invasion & intermediate & yes \\
\hline Nodule Bethesda IV & Bethesda IV & no contributory & 4 & & Minimally invasive FTC pT2 & low & no \\
\hline Nodule $>3 \mathrm{~cm}$ & Bethesda IV & no & 4 & & Minimally invasive FTC pT2 & low & no \\
\hline Nodule Bethesda IV & Bethesda IV & no & 0,9 & & Minimally invasive FTC pT1a & low & no \\
\hline Nodule $>3 \mathrm{~cm}$ & Bethesda IV & no & 5 & & Minimally invasive FTC pT3 & low & no \\
\hline Nodule $2 \mathrm{~cm}$ increase size & Bethesda I & no contributory & 1,5 & incidentaly & Minimally invasive FTC pT1b & low & no \\
\hline Nodule $3 \mathrm{~cm}$ & Bethesda I & no & 3,5 & incidentaly & Minimally invasive FTC pT2 with $>4$ foci of vascular invasion & high & yes \\
\hline Nodule Bethesda IV & Bethesda IV & no & $1,7+0,2$ & & Intrathyroidal PTC pT1bN1 0,5cm + PTMC & intermediate & yes \\
\hline
\end{tabular}


Table 4: Postoperative complications

\begin{tabular}{|l|c|c|c|}
\hline \multicolumn{1}{|c|}{ Parameters } & $\begin{array}{c}\text { Total } \\
\text { thyroidectomies } \\
\mathrm{N} \mathrm{( \% )} \\
\mathrm{N}=335\end{array}$ & $\begin{array}{c}\text { Hemithyroidectomies } \\
\mathrm{N}(\%) \\
\mathrm{N}=158\end{array}$ & p-values \\
& $77(23.0)$ & $0(0)$ & \\
\hline Calcium supplementation upon discharge & $36(10.7)$ & $0(0)$ & - \\
Hypocalcaemia at 1 month & $21(6.3)$ & $0(0)$ & - \\
Permanent hypocalcaemia & $16(4.8)$ & $6(3.8)$ & 0.62 \\
& $14(4.2)$ & $5(3.2)$ & 0.58 \\
Voice changed during hospitalisation & $6(1.8)$ & $3(1.9)$ & 1 \\
Confirmed recurrent laryngeal nerve palsy & $9 / 14(64.3)$ & $5 / 5(100)$ & 0.25 \\
Permanent palsy (6 month) & & & \\
$\quad$ Concordance with most affected lobe (21) & $4(1.2)$ & $5(3.2)$ & 0.15 \\
& & & \\
Haematoma & & & \\
\hline
\end{tabular}

Figure 1: Flow chart 


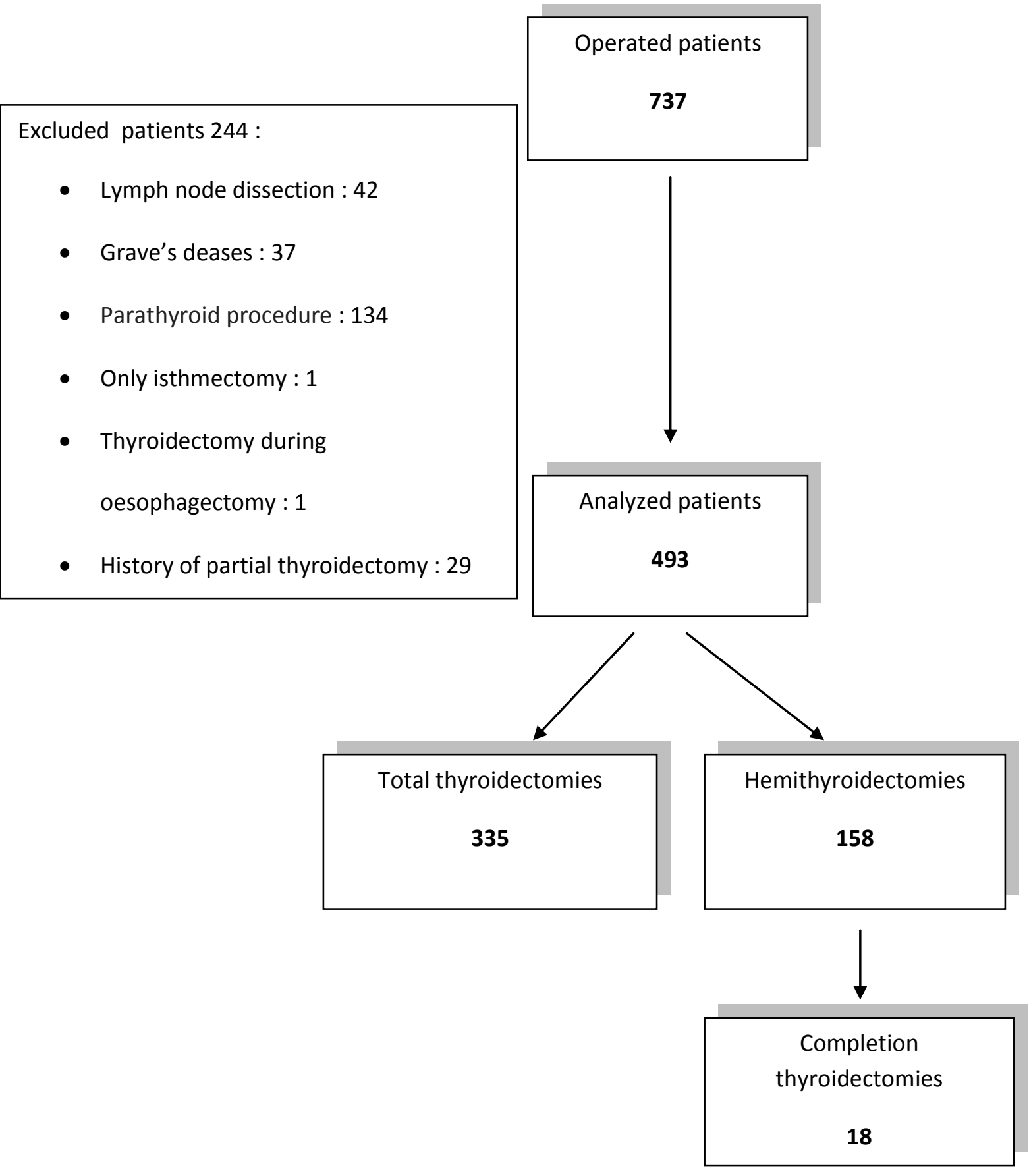

